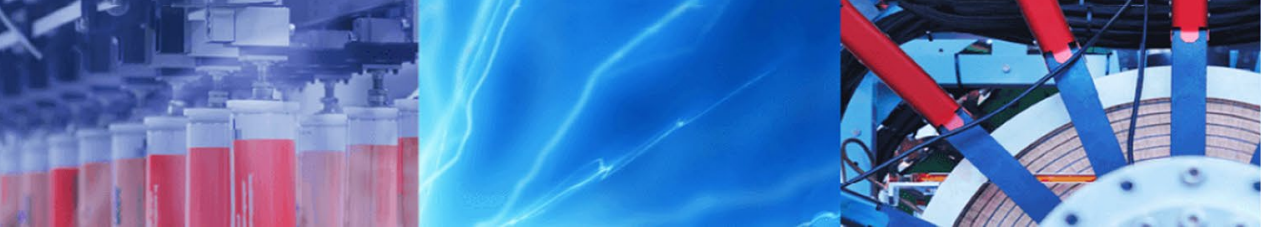

Research Article

\title{
Analysis and optimization of laser drilling process during machining of AISI 303 material using grey relational analysis approach
}

\author{
V. Chengal Reddy ${ }^{1} \cdot$ Thota Keerthi $^{1} \cdot$ T. Nishkala $^{1} \cdot$ G. Maruthi Prasad Yadav ${ }^{1}$
}

Received: 21 October 2020 / Accepted: 4 February 2021 / Published online: 16 February 2021

(C) The Author(s) 2021 OPEN

\begin{abstract}
Surface roughness and heat-affected zone (HAZ) are the important features which influence the performance of the laser-drilled products. Understanding the influence of laser process parameters on these responses and identifying the cutting conditions for simultaneous optimization of these responses are a primary requirement in order to improve the laser drilling performance. Nevertheless, no such contribution has been made in the literature during laser drilling of AISI 303 material. The aim of the present work is to optimize the surface roughness $\left(R_{a}\right)$ and HAZ in fibre laser drilling of AISI 303 material using Taguchi-based grey relational analysis (GRA). From the GRA methodology, the recommended optimum combination of process parameters is flushing pressure at $30 \mathrm{~Pa}$, laser power at $2000 \mathrm{~W}$ and pulse frequency at $1500 \mathrm{~Hz}$ for simultaneous optimization of $R_{a}$ and $\mathrm{HAZ}$, respectively. From analysis of variance, the pulse frequency is identified as the most influenced process parameters on laser drilling process performance.
\end{abstract}

Keywords Laser drilling process · Heat-affected zone - Surface roughness · ANOVA · Grey relational analysis · Optimization

\section{Introduction}

The demand for the stainless steel has been increasing tremendously in many fields of industries like automobiles, aviation, aerospace, medical science and household appliances because of their appreciative properties like low thermal conductivity, high strength to weight ratio and corrosion resistance [1]. These applications entail intricate cutting shapes and as well as different size holes. Products produced using conventional machining of this material lead to poor surface quality and product performance due to the tool vibration [2, 3]. Further, high burr formation in conventional drilling results in poor accuracy and high manufacturing cost $[2,3]$. Laser machining is emerged as an alternative for conventional machining to minimize the aforementioned effects. Application of laser in the drilling process has many advantages like non-contact machining operation, reproductively of drilled holes with high accuracy. Hence, in the literature, laser has been used in the drilling process during machining of AISI 303 material.

Wang et al. [4] investigated the effect of pulse duration, laser power and material property (elastic modulus) on delamination during Nd:YAG laser drilling of thermal barrier coated nickel alloy. Further, the finite element method (FEM) was used to predict the delamination and good agreement was observed between the predicted and experimental results. Furthermore, it was reported that quicker through holes were obtained at the higher peak power density due to the higher thermal stress shock and Stress mutation near the hole. Balakrishnan et al. [5] compared the delamination factor and cone angle while drilling of CFRP laminates using NC milling machine and $\mathrm{CO}_{2}$ lasers machining, respectively. From results, low delamination factor and cone angle were found in laser

$\triangle$ V. Chengal Reddy, vcr.312@gmail.com | 1 Department of Mechanical Engineering, Chadalawada Ramanamma Engineering College, Tirupati, Andhra Pradesh 517506, India. 
drilling when compared to the milling machine drilling due to the less thrust force. Marimuthu et al. [6] studied the effect of process parameters on micro-drill hole diameter and taper angle during fibre laser drilling of Nimonic 263 nickel superalloy and found that minimal diameter hole resulted in the combination of low pulse energy and low pulse duration. Biswas et al. [7] found optimum process parameters were identified during $A$ CNC-pulsed $\mathrm{Nd}$ :YAG laser machining of ceramic material $\left(\mathrm{TiN}-\mathrm{Al}_{2} \mathrm{O}_{3}\right.$ composites) using RSM approach. Chatterjee et al. [8] applied genetic algorithm and determined optimum laser process parameters namely laser energy, pulse repetition rate, pulse width and gas pressure while Nd:YAG microlaser machining of AISI 316. Circularity at entry, circularity at exit, taper, spatter area and heat-affected zone (HAZ), respectively, were considered as responses. Chen et al. [9] conducted experiments in nanosecond pulsed laser drilling of Si3N4 ceramic under water and air environments at varying scanning speed and depth of hole cutting conditions. From results, it was found larger taper angle in water at varying scanning speed condition whereas low taper angle was found at a high depth of hole condition.

Chien and Hou [10] examined the recast layer thickness in Nd:YAG laser trepan drilling of Inconel 718 material and Taguchi analysis has been applied to determine the optimum parameters. From the analysis, reduced recast layer thickness was observed at the Taguchi method determined optimum cutting conditions. Further, ANOVA was done to find the most influenced process parameters on recast layer thickness. Duan et al. [11] explored the burr formation using one factor at a time approach in laser trepan drilling process. Further, optimum process parameters have been identified using Taguchi technique. Goyal and Dubey [12] considered pulse width, pulse frequency, gas pressure and trepanning speed as process parameters and developed mathematical models for hole taper at entry and exit using regression analysis in laser trepan drilling of Inconel 718. Additionally, optimum cutting conditions were found using artificial neural network integrated GA approach. In another work by Goyal and Dubey [13], beneficial results were found in terms of hole taper and circularity by conducting experiments at the optimum conditions which were determined by using GA during laser drilling of titanium alloy. Mishra and Yadava [14] performed modelling and optimization studies by taking pulse width, pulse frequency and peak power as controllable process parameters and responses as hole taper, material removal rate (MRR) and heat-affected zone (HAZ) during laser drilling of Inconel 718. Further, significant improvement in laser drilling performance was observed at the optimum cutting conditions determined by using GRA coupled with Principal Component Analysis (PCA). In Parthiban et al. [15], optimum process parameters were identified using multi-objective optimization technique namely TOPSIS and observed improved performance in terms of surface roughness and surface crack density at the optimum conditions during drilling of nickel C263 material using picosecond Nd:YAG pulsed laser. Rajesh et al. [16] conducted experiments based on the $L_{31}$ CCD-based RSM design and developed mathematical models for circularity of drilled hole at entry and exit and taper are using RSM methodology in Nd:YAG laser drilling of austenitic stainless steel. Saini et al. [17] improved drilling process performance was observed at the optimum process parameters in terms of pulse width, pulse Frequency, trepanning Speed and assist gas pressure using GA during laser trepan drilling of Zirconia Toughened Alumina ceramic material. In Sibalija and Petronic [18], simultaneous optimization of seven performance characteristics has been performed during pulsed Nd:YAG laser drilling of Nimonic 263 using ANN coupled GA multi-objective optimization technique. Su et al. [19] have taken peak power and the ablation time as process parameter variables and hole diameter, hole circularity, taper angle and recast layer boron carbide were considered as performance characteristics in fibre laser drilling of B4C ceramic material. Experiments were performed based on one factor at a time approach and found to be $40 \mathrm{~W}$, $5.5 \mathrm{~ms}$, respectively, that are the peak power and ablation time to produce a hole with good quality. Wang et al. [20] experiments were performed on Cu50Zr50 amorphous alloys foils in Nd: YAG laser drilling process and studied the effect of process parameters namely laser power, laser pulse width and laser defocusing amount on average hole diameter. It was noticed the increase in hole diameter with increasing laser power, laser pulse width because of the rise in laser energy.

In any production line, processing cost and productivity significantly depend on the selection of process parameters. If it is a production line with machining work stations then machining cost and productivity largely depend on the performing machining operation at optimum cutting conditions. In machining work stations, optimum cutting conditions are required for simultaneous improvement of different performance characteristics including tool wear, surface roughness, cutting force, surface integrity, etc. Grey relational analysis is one of the promising multiobjective metaheuristic technique with a simple scientific methodology to select the cutting conditions for multiobjective optimization problems [21]. Recently, GRA has been used in metal cutting removal processes to improve performance. Avvari et al. [22] performed pulsed Nd:YAG laser drilling process on titanium alloy and grey relational analysis (GRA) has been applied to identify the optimum cutting conditions for improving the material removal rate (MRR) and hole taper angle. In Nakhjavani et al. [23], significant improvement in the Nd:YAG laser drilling 
of EN3 material was observed at the optimum process parameters identified by the GA technique. Panda et al. [24] performed experiments on high carbon steel Domex C67 material in pulsed $\mathrm{Nd}$ :YAG laser drilling process and achieved improved drilling process performance characteristics in terms of $\mathrm{HAZ}$, hole circularity and MRR using GRA approach. Aslantas et al.[25] determined optimum micro-milling process parameters during machining of Ti6Al-4 V alloy using GRA and obtained significant improvement in performance in terms of burr width and surface roughness at the optimum cutting conditions. Varghese et al. [26] achieved significant improvement in end milling process performance at the optimum cutting conditions which were identified using GRA method. Manikandan et al. [27] improved performance characteristics like material removal rate and surface roughness, overcut, form and orientation tolerance were observed at the optimum process parameters which were determined by using GRA method during Electrochemical Drilling process on Inconel 625 material. Correspondingly, performance improvement in cryogenic turning process was noticed using GRA [28-31]. Besides, various multi-objective optimization techniques were used to determine the optimum process variables during machining processes [32-34].

To the author's best understanding, countable literature is available in laser drilling of superalloys, ceramics and composite materials. However, the literature lacks on AISI 303 which have much application in the different fields. Yet again, tolerances limits of the drill hole are significantly depending on the surface roughness. Drilling a hole with meeting the stringent quality standards is a challenging task. As well, HAZ is one of the factors affects the performance of the drill hole greatly and producing a hole with low HAZ is a tricky undertaking. To fulfil modern manufacturing obligations, conducting the drilling experiments at the optimum cutting conditions is preference. Nevertheless, deciding the optimum cutting conditions is a fussy job due to the involvement of many process parameters. Therefore, the main objective of the present work is to determine the optimum cutting conditions in laser drilling of AISI 303 material using multi-objective optimization techniques. In this work, optimum fibre laser drilling process parameters were identified using Taguchi-based grey relational analysis (GRA) to simultaneously reduce the surface roughness and HAZ. Further, ANOVA has been carried to identify the most influenced process parameter in laser drilling process performance.

\section{Experimental works}

In the present work, Taguchi $\mathrm{L}_{9}$ orthogonal array (OA) design has been used to conduct experiments on AISI 303 material $(300 \times 150 \times 6 \mathrm{~mm})$ using fibre laser drilling machine. Each experiment was conducted three times and average was taken as final output values to get the accuracy in the data. Mechanical properties of the AISI 303 material are as follows: Hardness, Vickers:240; Tensile Strength, Ultimate: $690 \mathrm{MPa}$; Tensile Strength, Yield: $415 \mathrm{MPa}$; Elongation at Break: 40\%; Proof Stress: $190 \mathrm{MPa}$; Modulus of Elasticity: $193 \mathrm{GPa}$. Figure 1 depicts the laser drilling experimental set-up. Specifications of the laser machine as follows: An IPG Quasi-CW fibre laser that can operate at a maximum average power of $3000 \mathrm{~W}$,

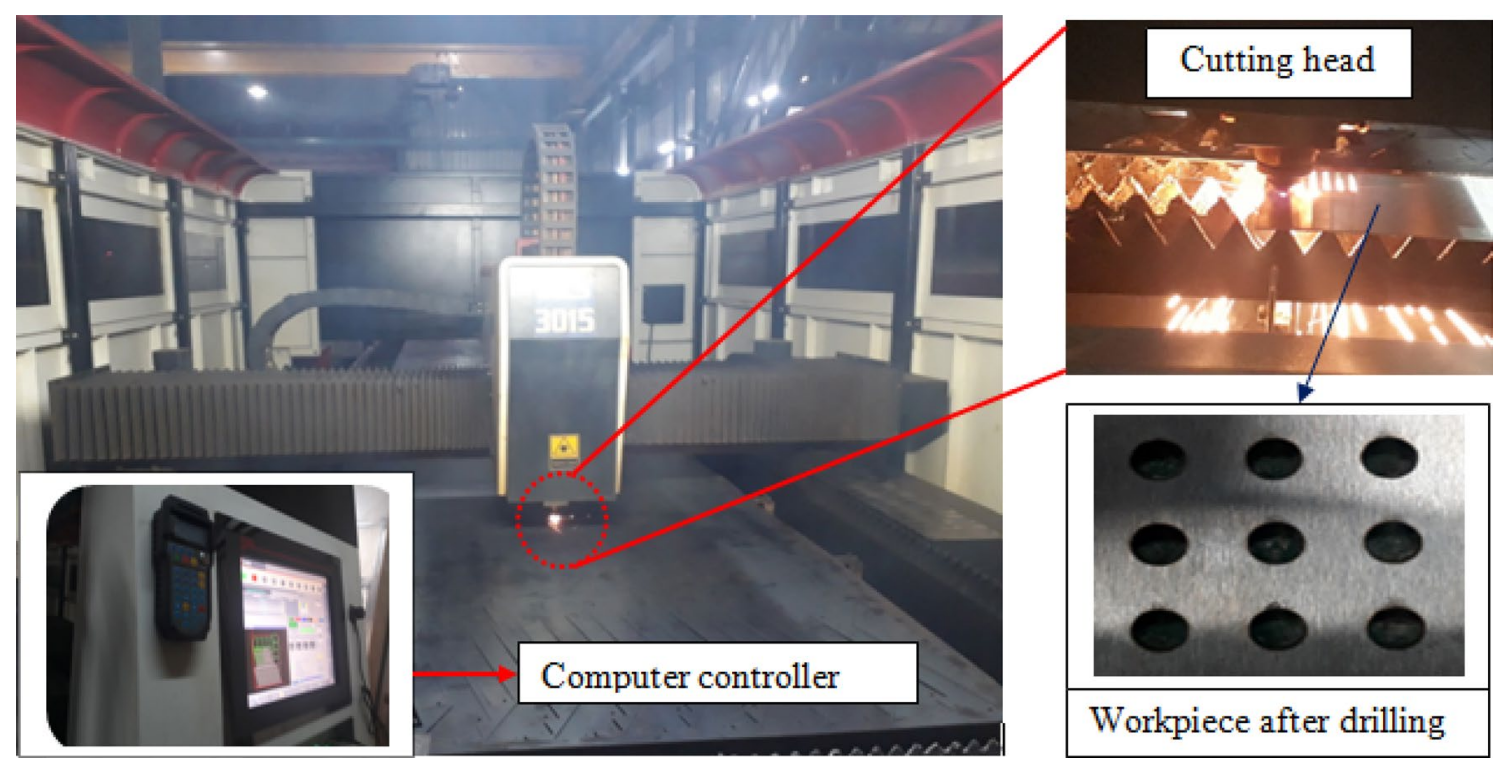

Fig. 1 Laser drilling experimental set-up 
Table 1 Laser process parameters and their levels

\begin{tabular}{llllll}
\hline Symbol & Process parameters & Units & \multicolumn{2}{l}{ Levels } \\
\cline { 3 - 6 } & & & 1 & 2 & 3 \\
\hline$F P$ & Flushing pressure & $\mathrm{Pa}$ & 25 & 30 & 35 \\
$L P$ & Laser power & $\mathrm{W}$ & 2000 & 2250 & 2500 \\
$P F$ & Pulse frequency & $\mathrm{Hz}$ & 1500 & 2000 & 2500 \\
\hline
\end{tabular}

Table 2 Plan of experiments and experimental results

\begin{tabular}{|c|c|c|c|c|c|}
\hline \multirow[t]{2}{*}{ Exp. runs } & \multicolumn{3}{|c|}{$\begin{array}{l}\text { Controllable process } \\
\text { parameters }\end{array}$} & \multicolumn{2}{|c|}{ Experimental results } \\
\hline & $F P$ & $L P$ & $P F$ & $R_{a}(\mu \mathrm{m})$ & $H A Z(\mu \mathrm{m})$ \\
\hline 1 & 1 & 1 & 1 & 1.76 & 32.17 \\
\hline 2 & 1 & 2 & 2 & 2.6213 & 32.87 \\
\hline 3 & 1 & 3 & 3 & 2.2143 & 61.09 \\
\hline 4 & 2 & 1 & 2 & 2.035 & 28.79 \\
\hline 5 & 2 & 2 & 3 & 2.618 & 34.62 \\
\hline 6 & 2 & 3 & 1 & 1.7743 & 53.13 \\
\hline 7 & 3 & 1 & 3 & 2.684 & 32.99 \\
\hline 8 & 3 & 2 & 1 & 1.9943 & 31.55 \\
\hline 9 & 3 & 3 & 2 & 1.925 & 52.15 \\
\hline
\end{tabular}

maximum peak power of $20 \mathrm{~kW}$ and pulse duration ranging from 0.1 to $10 \mathrm{~ms}$ was used as the laser source. The Taguchi $L_{9}$ OA design was employed to explore the analysis due to the necessity of minimum effort and low manufacturing cost [35]. Process parameters considered in the present study are shown in Table 1. In the present study, the laser beam diameter of $200 \mu \mathrm{m}$ and stand-off distance of $1 \mathrm{~mm}$ were considered during laser drilling. Nitrogen $\left(\mathrm{N}_{2}\right)$ gas is utilized as assistant gas to remove molten metal during the laser drilling process. Preliminary experiments were conducted to select the range for each process parameter. Design of Experiment (DOE) concept was used to select the levels for each process variable. A diameter of $6 \mathrm{~mm}$ through hole is made in each experiment after that heat-affected zone (HAZ) and average surface roughness $\left(R_{a}\right)$ were measured as outputs in the present study. Optical microscope is employed to measure the HAZ. For surface roughness measurement, drilling hole is cut into half cross-sectional and Mitutoyo makes SJ-310 model probe contact type has been used to measure the average surface roughness. A cut of length of $0.8 \mathrm{~mm}$ and a sample length of $4 \mathrm{~mm}$ was considered during $\mathrm{R}_{\mathrm{a}}$ value measurement for each drill surface. Surface rough was measured based on the ISO 4287-1997 standards. Surface morphology of drilled surfaces was investigated using 'ZEISS' Scanning Electron Microscope (SEM). Experimental results after measuring the results are shown in Table 2.

\section{Results and discussion}

\subsection{Grey relational analysis (GRA)}

GRA solves the problems of any system in which relationship among the various multiple performance characteristics and factors is complicated or unclear. Selecting the right alternative among the more available choices is not an easy assignment. Therefore, a systematic and scientific methodology is required to solve such a difficult task. The researchers have shifted their concentration towards GRA because of easy understanding and simple methodology. In the present work, the relation between the process parameters and performance characteristics is unclear during laser drilling of AISI 303 material and selection of the right alternative which improves the laser performance is a difficult task. Hence, in the present work, Taguchi-based GRA was employed to identify the right choice a following steps to choose the right alternative among available alternatives [36-38].

\subsection{Data preprocessing or normalization}

Since the ranges of the two responses in the present study are not the same, therefore data processing is a necessity to perform to nullify the range difference. In this step, the original response data $\left(\left(D_{p}{ }^{*}(q)\right)\right.$ were converted into the range between 0 and $1\left(0 \leq D_{p}{ }^{*}(q) \leq 1\right)$. Data processing can be done based upon the requirement of characteristic to improve the laser drilling process performance. Grey system recommends Eq. (1) for lower the better characteristics. In the present work, HAZ and surface roughness are the lower the better to improve the laser process performance. Therefore, data processing has been done using Eq. (1) and results are shown in Table 3.

Smaller - the - better : $D_{p}^{*}(q)=\frac{\operatorname{Max} D_{p}(q)-D_{p}(q)}{\operatorname{Max} D_{p}(q)-\operatorname{Min} D_{p}(q)}$,

where $D_{p}{ }^{*}(q)=$ data processing sequence, $D_{p}(q)=$ Original sequence, $\operatorname{Max} D_{p}(q)=$ Maximum value of entity ' $p$ ', $\operatorname{Min} D_{p}(q)=$ Minimum value of entity ' $p$ ', $p=$ Number of characteristics $(1,2), q=$ Number of experimental runs $(1$, $2, \ldots \ldots, 9)$.

\subsection{Grey relational coefficients (GRC)}

In this step, normalized data $\left(D_{p}{ }^{*}(q)\right)$ was used to calculate the GRC values of each response $\left(\varepsilon_{p}(q)\right)$. This step 
Table 3 Performance characteristics GRC, GRG, S/N ratio and its order

\begin{tabular}{|c|c|c|c|c|c|c|}
\hline \multirow[t]{4}{*}{ Exp. No } & \multicolumn{2}{|c|}{$\begin{array}{l}\text { Normalized values of Per- } \\
\text { formance characteristics }\end{array}$} & \multicolumn{2}{|c|}{$\begin{array}{l}\text { Grey relational coefficient } \\
\text { (GRC) }\end{array}$} & \multirow[t]{4}{*}{$\begin{array}{l}\text { Grey relational } \\
\text { grade (GRG) }\end{array}$} & \multirow[t]{4}{*}{ Order } \\
\hline & \multirow[t]{3}{*}{$R_{a}$} & \multirow[t]{3}{*}{$\mathrm{HAZ}$} & $R_{a}$ & $\mathrm{HAZ}$ & & \\
\hline & & & \multicolumn{2}{|c|}{ Ideal sequence } & & \\
\hline & & & 1 & 1 & & \\
\hline 1 & 1.0000 & 0.8954 & 1.0000 & 0.8269 & 0.9135 & 1 \\
\hline 2 & 0.0679 & 0.8737 & 0.3491 & 0.7983 & 0.5737 & 5 \\
\hline 3 & 0.5083 & 0 & 0.5042 & 0.3333 & 0.4188 & 9 \\
\hline 4 & 0.7024 & 1.0000 & 0.6269 & 1.0000 & 0.8134 & 2 \\
\hline 5 & 0.0714 & 0.8195 & 0.3500 & 0.7348 & 0.5424 & 8 \\
\hline 6 & 0.9845 & 0.2464 & 0.9700 & 0.3989 & 0.6844 & 4 \\
\hline 7 & 0 & 0.8700 & 0.3333 & 0.7936 & 0.5635 & 7 \\
\hline 8 & 0.7464 & 0.9146 & 0.6635 & 0.8540 & 0.7588 & 3 \\
\hline 9 & 0.8214 & 0.2768 & 0.7368 & 0.4088 & 0.5728 & 6 \\
\hline
\end{tabular}

signifies the closeness between the reference sequence and comparability sequence using GRC. Equation (2) was used to calculate the $\varepsilon_{\mathrm{p}}(\mathrm{q})$ values for each response and results are shown in Table 3.

$\varepsilon_{p}(q)=\frac{\Delta_{\mathrm{Min}}+\zeta \Delta_{\mathrm{Max}}}{\Delta_{p q}+\zeta \Delta_{\operatorname{Max}}}$

Here, reference sequence $\Delta_{p q}$ is calculated using Eq. (3) and it is an absolute difference between the normalized data $\left(D_{p}{ }^{*}(q)\right)$ and ideal data (1). Distinguishing coefficient

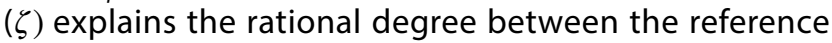
sequence and comparability sequence. In the present work, authors are given equal importance to the two responses, therefore, $\zeta=0.5$ considered. $\Delta_{\text {Min }}$ and $\Delta_{\text {Max }}$ were calculated using Eqs. (3) and (4), respectively.

$\Delta_{\text {Min }}=\min _{p} \min _{q} \Delta_{p q}$

$\Delta_{\operatorname{Max}}=\max _{p} \max _{q} \Delta_{p q}$

\subsection{Grey relational grade (GRG)}

Grey relational grade $\left(\gamma_{p}(q)\right)$ is the index used to evaluate the multiple performance characteristics. To obtain experimental results close to the ideal solution, the highest GRG is essential. Highest GRG value characterizes the best alternative solution. Equation (5) is used to calculate the $\gamma_{p}(q)$ and results are shown in Table 3.

$\gamma_{p}(q)=\frac{1}{N} \sum_{i=0}^{N}\left[\omega_{p} * \varepsilon_{p}(q)\right]=\frac{1}{N} \sum_{i=0}^{N} \varepsilon_{p}(q)$, where $N=$ No. of performance characteristics, $\omega_{p}=$ Weightage given for each response (equal importance is given for both response).

Based on the obtained GRG values of performance characteristics, the rank was awarded in such a way that the highest GRG value is ranked as 1. Highest GRG value indicates the corresponding performance characteristics are close to the ideal solution. Further, GRG is considered as the one response and applied Taguchi methodology to determine the optimum cutting conditions. In Taguchi methodology, GRG is selected as the maximum better requirement and Minitab 17.0 is used to obtain the response table for GRG values as listed in Table 4. From Table 4, cutting parameters of flushing pressure at $30 \mathrm{~Pa}$, laser power at $2000 \mathrm{~W}$ and pulse frequency at $1500 \mathrm{~Hz}$ were determined as the predicted optimum process parameters $\left(F P_{2}-L P_{1}-P F_{1}\right)$ during laser drilling of AISI 303 material.

\section{Confirmation test results}

Conformation test is conducted to validate the predicted optimum process parameters and results are shown in Table 5. The predicted GRG value at the predicted

Table 4 Mean response for GRG

\begin{tabular}{llll}
\hline Level & $F P$ & $L P$ & $P F$ \\
\hline 1 & 0.6353 & 0.7635 & 0.7856 \\
2 & 0.6801 & 0.625 & 0.6533 \\
3 & 0.6317 & 0.5587 & 0.5082 \\
Max-Min & 0.0484 & 0.2048 & 0.2773 \\
Rank & 3 & 2 & 1 \\
\hline
\end{tabular}


Table 5 Conformation test results

\begin{tabular}{llll}
\hline & $\begin{array}{l}\text { Initial process } \\
\text { parameter }\end{array}$ & $\begin{array}{l}\text { Optimal process param- } \\
\text { eters }\end{array}$ \\
\cline { 3 - 4 } \cline { 3 - 4 } & & Prediction & Experiment \\
\hline Level & $F P_{1}-L P_{1}-P F_{1}$ & $F P_{2}-L P_{1}-P F_{1}$ & $F P_{2}-L P_{1}-P F_{1}$ \\
$R_{a}(\mu \mathrm{m})$ & 1.76 & & 1.52 \\
$H A Z(\mu \mathrm{m})$ & 32.17 & & 29.5 \\
Grey relation grade & 0.9135 & & 0.9310 \\
\hline
\end{tabular}

optimum process parameters is calculated using Eq. (6) and result is shown in Table 5.

$\gamma_{\text {predicted }}=\gamma_{m}+\sum_{i=1}^{k}\left(\gamma_{o}-\gamma_{m}\right)$,

where $\gamma_{m}=$ Average of total grey relational grade; $\gamma_{o}=$ the mean of the grey relational grade at the optimal levels; $k=$ Total number of the machining parameters.

It is seen from Table 5 that predicted optimum process parameters $\left(F P_{2}-L P_{1}-P F_{1}\right)$ significantly reduced the $\mathrm{HAZ}$ and surface roughness to $8 \%$ and $14 \%$ when compared to initial process parameter conditions $\left(F P_{1}-L P_{1}-P F_{1}\right)$. Therefore, flushing pressure at $30 \mathrm{~Pa}$, laser power at $2000 \mathrm{~W}$ and pulse frequency at $1500 \mathrm{~Hz}$ were determined as the predicted optimum process parameters $\left(F P_{2}-L P_{1}-P F_{1}\right)$ during laser drilling of AISI 303 material.

\section{Effect of process parameters on HAZ and surface roughness}

\subsection{Heat-affected zone (HAZ)}

Figure 2 depicts the influence of process parameters on HAZ. HAZ thickness reduces with an increase in assistance gas pressure. Removal of more molten metal from the laser-workpiece interaction at the high gas pressure attributed to low HAZ thickness. Microscope images were captured at the given cutting conditions as depicted in Fig. 3. It is evident that high gas pressure produces low HAZ thickness as depicted in Fig. 3. It is found that increase in HAZ thickness with respect to the rise in laser power. When laser power increases then the amount of energy increase causes the flow of more molten metal at the top surface of the hole leads to more heating of the hole edge hence high HAZ thickness. From Fig. 4, it is observed that increased HAZ thickness at high peak power cutting conditions. It is found that HAZ thickness has an increasing trend towards a rise in pulse frequency due to the more molten metal at the top surface of the hole. It is evident that HAZ thickness is more at the high pulse conditions as seen in Fig. 5. Higher temperature at high pulse cutting conditions is responsible for high $\mathrm{HAZ}$. The results obtained in the present work are well agreed with the literature results [8].

\subsection{Surface roughness}

Figure 6 shows the influence of laser process parameters gas pressure, pulse frequency and laser power on surface roughness. From 6 , it is found that surface roughness increases when process parameters increase. The amount of thermal energy and mechanical force that melt and remove deeper grooves at the higher process parameters are responsible for high surface roughness. From Figs. 7 and 8, it is evident that higher laser process parameters produced drill hole surface morphology with higher surface roughness. In the literature also, Chen et al. [9] found similar kind of results in laser drilling process.
Fig. 2 Effect of process parameters on $\mathrm{HAZ}$

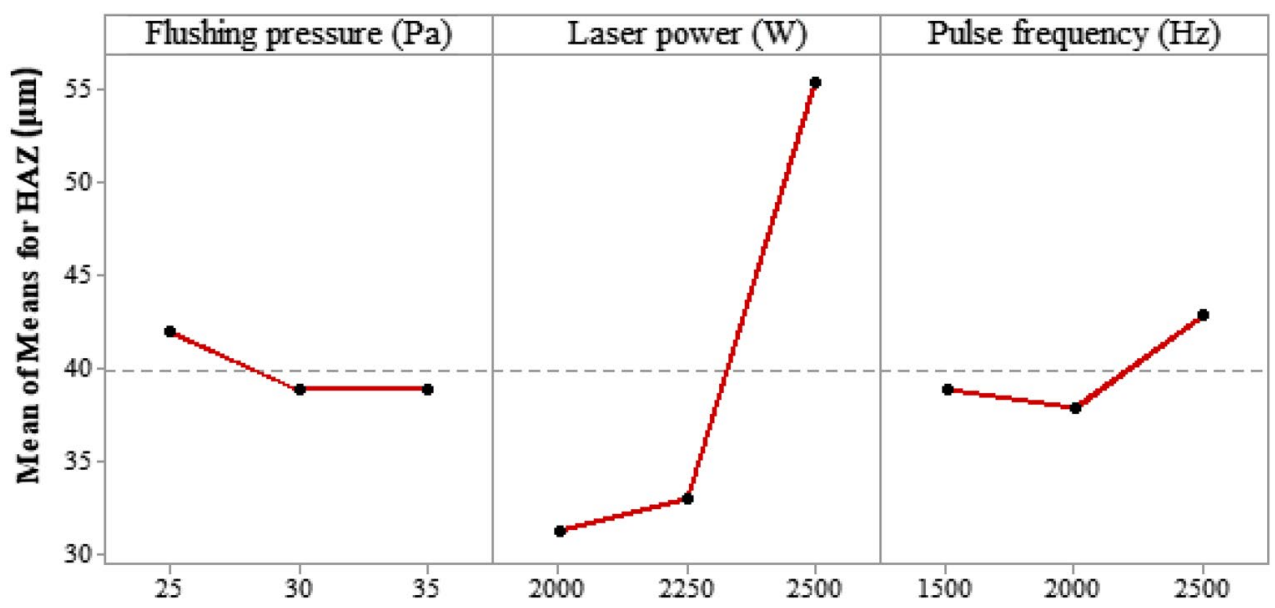

SN Applied Sciences 


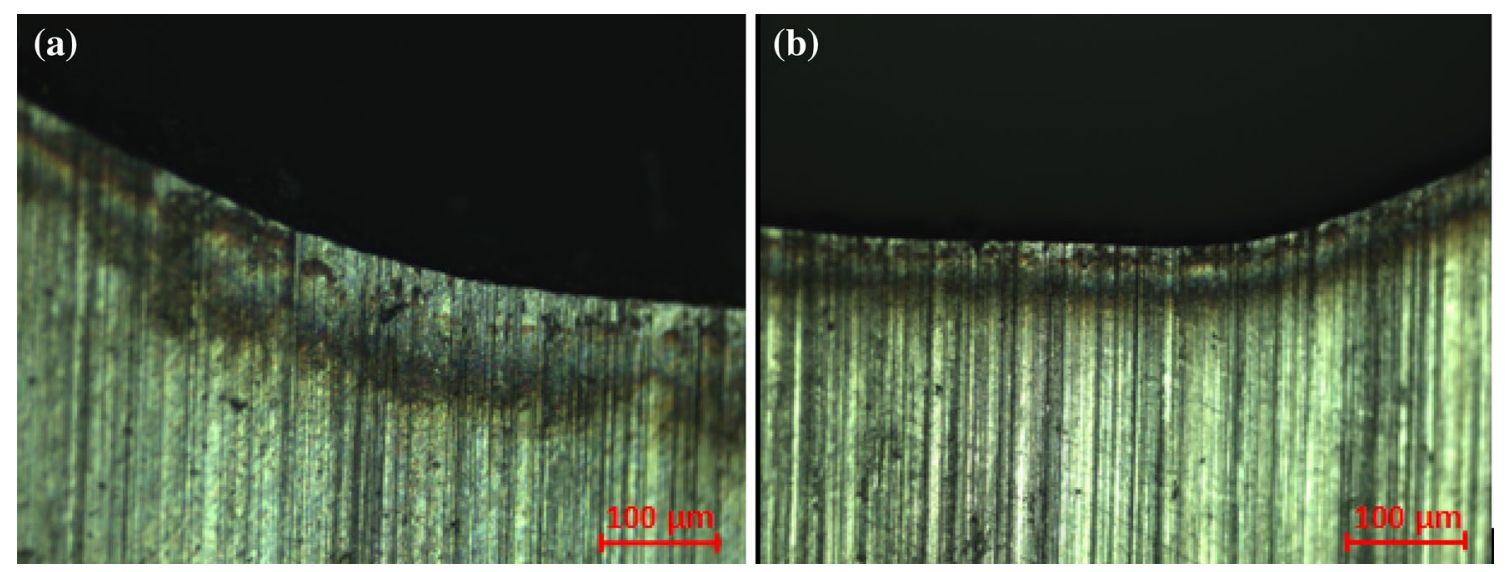

Fig. $3 \mathrm{HAZ}$ obtained at cutting conditions: (a) $F P=25 \mathrm{~Pa}, L P=2250 \mathrm{~W}$ and $P F=2000 \mathrm{~Hz}$ and (b) $F P=35 \mathrm{~Pa}, L P=2250 \mathrm{~W}$ and $P F=1500 \mathrm{~Hz}$
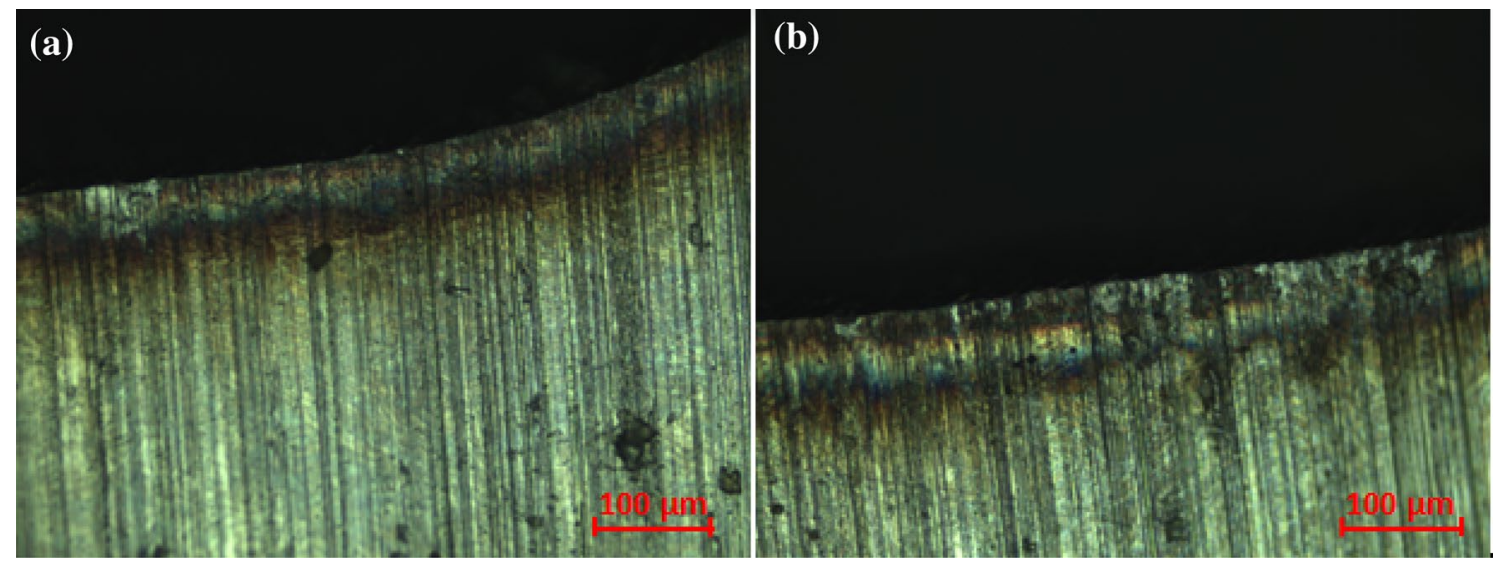

Fig. $4 \mathrm{HAZ}$ obtained at cutting conditions: (a) $F P=35 \mathrm{~Pa}, L P=2000 \mathrm{~W}$ and $P F=2500 \mathrm{~Hz}$ and (b) $F P=25 \mathrm{~Pa}, L P=2500 \mathrm{~W}$ and $P F=2500 \mathrm{~Hz}$
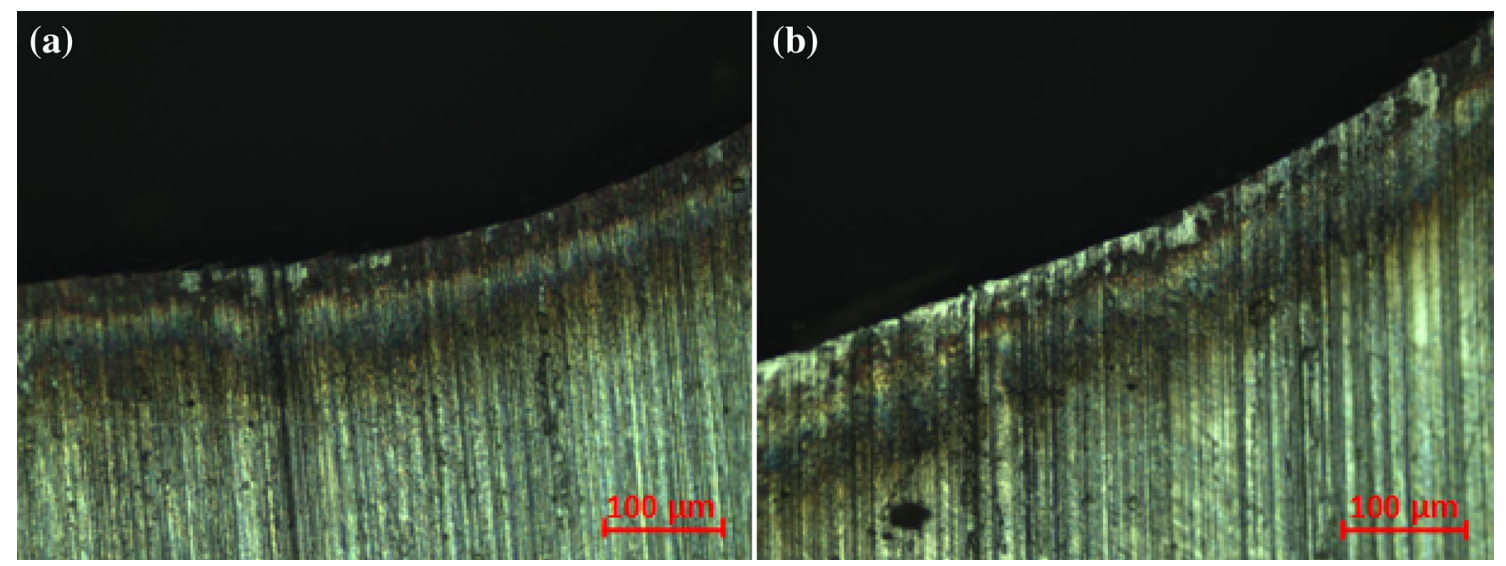

Fig. $5 \mathrm{HAZ}$ obtained at cutting conditions: (a) $F P=30 \mathrm{~Pa}, L P=2000 \mathrm{~W}$ and $P F=2000 \mathrm{~Hz}$ and (b) $F P=30 \mathrm{~Pa}, L P=2250 \mathrm{~W}$ and $P F=2500 \mathrm{~Hz}$ 
Fig. 6 Effect of process parameters on surface roughness

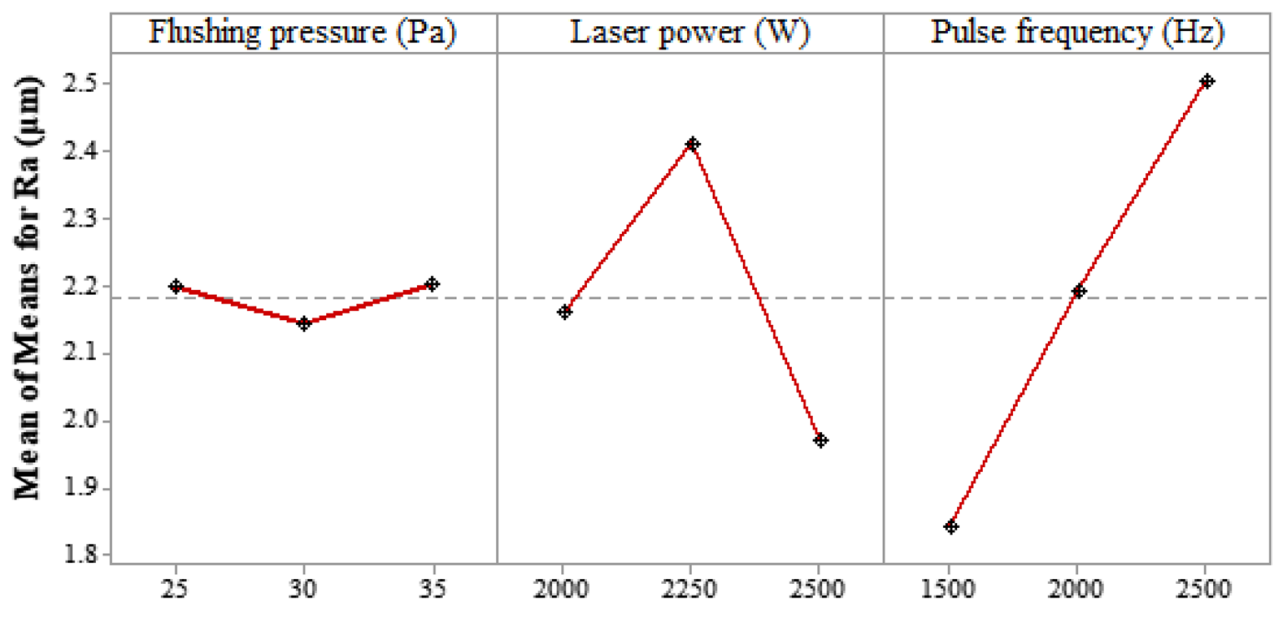

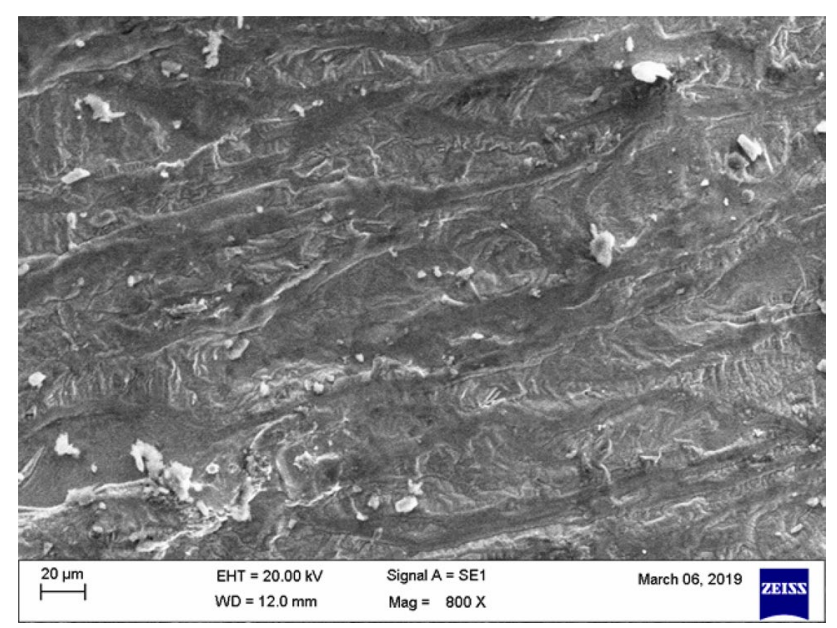

Fig. 7 Surface morphology of drilling hole at $F P=25 \mathrm{~Pa}$, $L P=2500 \mathrm{~W}$ and $P F=2500 \mathrm{~Hz}$ cutting conditions

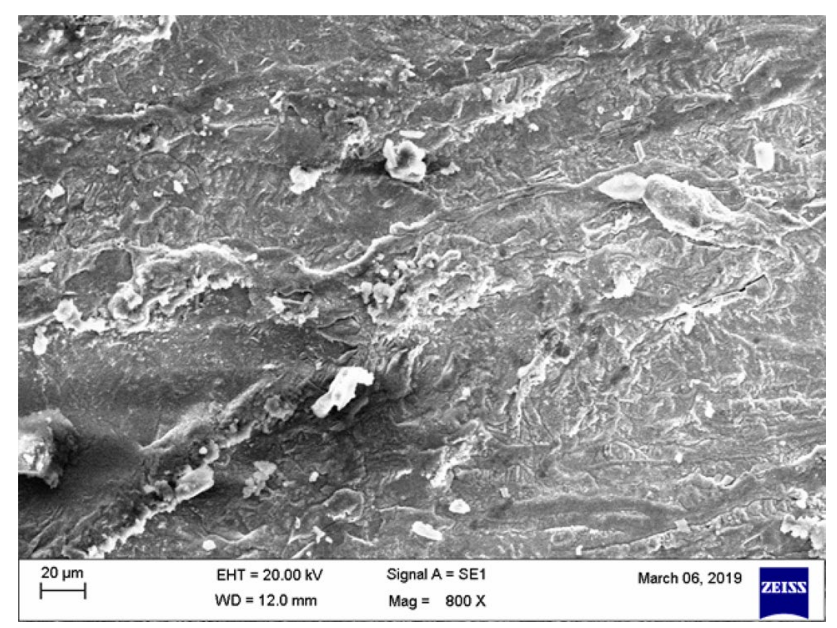

Fig. 8 Surface morphology of drilling hole at $F P=35 \mathrm{~Pa}$, $L P=2000 \mathrm{~W}$ and $P F=2500 \mathrm{~Hz}$ cutting conditions

\section{Analysis of variance (ANOVA)}

Grey relational grade (GRG) value is treated as one variable and ANOVA has been carried out on GRG using Minitab 17.0 software. Table 6 shows the ANOVA for GRG. From Table 6, it is found that pulse frequency has a significant contribution to laser drilling performance (GRG) following laser power and flushing pressure, respectively.

\section{Conclusions}

- The laser drilling process parameter flushing pressure at $30 \mathrm{~Pa}$, laser power at $2000 \mathrm{~W}$ and pulse frequency at $1500 \mathrm{~Hz}$ were chosen as the optimum process parameter using GRA.

- Taguchi-based GRA significantly reduced the HAZ and surface roughness to $8 \%$ and $14 \%$ when compared to initial process parameter conditions during machining of AISI 303 material.

- Machining cost could be reduced by conducting experiments at the Taguchi-based GRA identified optimum cutting conditions in the production line consists of laser the drilling operation during machining of AISI 303 material.

- Fewer surface defects were noticed in the lower levels of laser process parameters compared to higher levels of laser process parameters. 
Table 6 ANOVA of grey relational grade

\begin{tabular}{llllllc}
\hline Source & DOF & Sum of squares & Mean square & $F$ value & $P$ value & \% contribution \\
\hline A & 2 & 0.004354 & 0.002177 & 0.54 & 0.651 & 2.25 \\
B & 2 & 0.065521 & 0.032760 & 8.08 & 0.110 & 33.87 \\
C & 2 & 0.115453 & 0.057726 & 14.23 & 0.066 & 59.68 \\
Residual error & 2 & 0.008112 & 0.004056 & & & 4.2 \\
Total & 8 & 0.193439 & & & & 100 \\
\hline
\end{tabular}

Code availability Not applicable.

Data availability Not applicable.

\section{Compliance with ethical standards}

Conflict of interest The authors declare that they have no conflict of interest.

Open Access This article is licensed under a Creative Commons Attribution 4.0 International License, which permits use, sharing, adaptation, distribution and reproduction in any medium or format, as long as you give appropriate credit to the original author(s) and the source, provide a link to the Creative Commons licence, and indicate if changes were made. The images or other third party material in this article are included in the article's Creative Commons licence, unless indicated otherwise in a credit line to the material. If material is not included in the article's Creative Commons licence and your intended use is not permitted by statutory regulation or exceeds the permitted use, you will need to obtain permission directly from the copyright holder. To view a copy of this licence, visit http://creativecommons .org/licenses/by/4.0/.

\section{References}

1. Pereira O, Rodríguez A, Fernández-Abia Al, Barreiro J, de Lacalle LL (2016) Cryogenic and minimum quantity lubrication for an eco-efficiency turning of AISI 304. J Clean Prod 139:440-449. https://doi.org/10.1016/j.jclepro.2016.08.030

2. Xia T, Kaynak Y, Arvin C, Jawahir IS (2016) Cryogenic coolinginduced process performance and surface integrity in drilling CFRP composite material. Int J Adv Manuf Technol 82(1-4):605616. https://doi.org/10.1007/s00170-015-7284-y

3. Percin M, Aslantas K, Ucun I, Kaynak Y, Çicek A (2016) Microdrilling of Ti-6Al-4V alloy: the effects of cooling/lubricating. Precis Eng 45:450-462. https://doi.org/10.1016/j.precisione ng.2016.02.015

4. Wang R, Duan W, Wang K, Dong X, Fan Z, Mei X, Wang W, Zhang $S$ (2018) Computational and experimental study on hole evolution and delamination in laser drilling of thermal barrier coated nickel superalloy. Opt Lasers Eng 107:161-175. https://doi. org/10.1016/j.optlaseng.2018.03.019

5. Balakrishnan VS, Seidlitz H, Yellur MR, Vogt N (2018) A study on the influence of drilling and $\mathrm{CO}_{2}$ laser cutting in carbon/ epoxy laminates. Integr Med Res. https://doi.org/10.1016/j. jmrt.2018.05.025

6. Marimuthu S, Antar M, Dunleavey J (2019) Characteristics of micro-hole formation during fibre laser drilling of aerospace superalloy. Precis Eng 55:339-348. https://doi.org/10.1016/j. precisioneng.2018.10.002
7. Biswas R, Kuar AS, Biswas SK, Mitra S (2010) Characterization of hole circularity in pulsed Nd: YAG laser micro-drilling of TiN$\mathrm{Al}_{2} \mathrm{O}_{3}$ composites. Int J Adv Manuf Technol 51(9-12):983-994. https://doi.org/10.1007/s00170-010-2691-6

8. Chatterjee S, Mahapatra SS, Bharadwaj V, Choubey A, Upadhyay BN, Bindra KS (2018) Quality evaluation of micro drilled hole using pulsed Nd: YAG laser: a case study on AISI 316. Lasers Manuf Mater Process 5(3):248-269

9. Chen Q, Wang HJ, Lin DT, Zuo F, Zhao ZX, Lin HT (2018) Characterization of hole taper in laser drilling of silicon nitride ceramic under water. Ceram Int 44(11):13449-13452. https:// doi.org/10.1016/j.ceramint.2018.04.173

10. Chien WT, Hou SC (2007) Investigating the recast layer formed during the laser trepan drilling of Inconel 718 using the Taguchi method. Int J Adv Manuf Technol 33(3-4):308-316. https://doi. org/10.1007/s00170-006-0454-1

11. Duan W, Wang K, Dong X, Mei X, Wang W, Fan Z (2015) Experimental characterizations of burr deposition in Nd: YAG laser drilling: a parametric study. Int J Adv Manuf Technol 76(912):1529-1542. https://doi.org/10.1007/s00170-014-6377-3

12. Goyal R, Dubey AK (2014) Quality improvement by parameter optimization in laser trepan drilling of superalloy sheet. Mater Manuf Process 29(11-12):1410-1416. https://doi. org/10.1080/10426914.2014.912313

13. Goyal R, Dubey AK (2016) Modeling and optimization of geometrical characteristics in laser trepan drilling of titanium alloy. J Mech Sci Technol 30(3):1281-1293. https://doi. org/10.1007/s12206-016-0233-3

14. Mishra S, Yadava V (2013) Modeling and optimization of laser beam percussion drilling of nickel-based superalloy sheet using Nd: YAG laser. Opt Lasers Eng 51(6):681-695. https:// doi.org/10.1016/j.optlaseng.2013.01.006

15. Parthiban K, Duraiselvam M, Manivannan R (2018) TOPSIS based parametric optimization of laser micro-drilling of TBC coated nickel based superalloy. Opt Laser Technol 102:32-39. https://doi.org/10.1016/j.optlastec.2017.12.012

16. Rajesh P, Nagaraju U, Gowd GH, Vardhan TV (2017) Experimental and parametric studies of Nd: YAG laser drilling on austenitic stainless steel. Int J Adv Manuf Technol 93(1-4):65-71. https://doi.org/10.1007/s00170-015-7639-4

17. Saini SK, Dubey AK, Upadhyay BN, Choubey A (2018) Study of hole characteristics in laser trepan drilling of ZTA. Opt Laser Technol 103:330-339. https://doi.org/10.1016/j.optla stec.2018.01.052

18. Sibalija TV, Petronic SZ, Majstorovic VD, Prokic-Cvetkovic R, Milosavljevic A (2011) Multi-response design of Nd: YAG laser drilling of Ni-based superalloy sheets using Taguchi's quality loss function, multivariate statistical methods and artificial intelligence. Int J Adv Manuf Technol 54(5-8):537-552. https ://doi.org/10.1007/s00170-010-2945-3

19. Su L, Chen R, Huang Z, Zhou M, Zeng Q, Shi Q, Liao Z, Lu T (2018) Geometrical morphology optimisation of laser drilling in B4C ceramic: from plate to hollow microsphere. 
Ceram Int 44(2):1370-1375. https://doi.org/10.1016/j.ceram int.2017.08.206

20. Wang $C$, Xue $S$, Chen $G$, Luan D, Wang S, Wang Y, Wang S, Liu J, Wang Z, Zhang P (2018) Influence of laser parameters on micro-hole drilling of Cu50Zr50 amorphous alloys foil. Ferroelectrics 523(1):61-66. https://doi.org/10.1080/00150 193.2018.1391557

21. Deng JL (1982) Control problems of grey systems. Sys Contr Lett 1(5):288-294

22. Avvari $M$, Manjaiah $M, A b l M$, Laubscher RF, Raghavendra $K$ (2017) Optimization of hole characteristics during pulse Nd: YAG laser drilling of commercially pure titanium alloy. Lasers Manuf Mater Process 4(2):76-91. https://doi.org/10.1007/ s40516-017-0038-y

23. Nakhjavani OB, Ghoreishi M (2006) Multi criteria optimization of laser percussion drilling process using artificial neural network model combined with genetic algorithm. Mater Manuf Process 21(1):11-18. https://doi.org/10.1081/AMP-200060402

24. Panda S, Mishra D, Biswal BB (2011) Determination of optimum parameters with multi-performance characteristics in laser drilling - a grey relational analysis approach. Int J Adv Manuf Technol 54(9-12):957-967. https://doi.org/10.1007/ s00170-010-2985-8

25. Aslantas K, Ekic E, Çiçek A (2018) Optimization of process parameters for micro milling of Ti-6Al-4V alloy using Taguchi-based gray relational analysis. Measurement 128:419-427

26. Varghese V, Ramesh MR, Chakradhar D (2018) Experimental investigation and optimization of machining parameters for sustainable machining. Mater Manuf Process 33(16):1782-1792. https://doi.org/10.1080/10426914.2018.1476760

27. Manikandan N, Kumanan S, Sathiyanarayanan C (2017) Multiple performance optimization of electrochemical drilling of Inconel 625 using Taguchi based grey relational analysis. Eng Sci Technol an Int J 20(2):662-671

28. Sivaiah P, Chakradhar D (2017) Multi-objective optimisation of cryogenic turning process using Taguchi-based grey relational analysis. Int J Mach Mach Mater 19(4):297-312. https://doi. org/10.1504/IJMMM.2017.086161

29. Sivaiah P, Chakradhar D (2018) Multi performance characteristics optimization in cryogenic turning of $17-4 \mathrm{PH}$ stainless steel using Taguchi coupled grey relational analysis. Adv Mater Process Technol 4(3):431-447. https://doi.org/10.1080/23740 $68 X .2018 .1452132$

30. Sivaiah P, Chakradhar D (2019) Performance improvement of cryogenic turning process during machining of $17-4 \mathrm{PH}$ stainless steel using multi objective optimization techniques. Measurement 136:326-336. https://doi.org/10.1016/j.measuremen t.2018.12.094

31. Sivaiah P, Mallikarjuna P, Uma B, Chalapathi KV (2018) Optimization of environmental friendly turning process using Taguchi integrated grey relational analysis during machining of 17-4 PH stainless steel. i Manag J Mech Eng 8(4):8

32. Das PP, Chakraborty S (2020) Application of superiority and inferiority multi-criteria ranking method for parametric optimization of laser cutting processes. Process Integr Optim Sustain 4(4):409-427

33. Sarfraz $S$, Shehab E, Salonitis K, Suder W, Niamat M, Jamil M (2020) An integrated analysis of productivity, hole quality and cost estimation of single-pulse laser drilling process. Inst Mech Eng Part B J Eng. Manuf, Proc, p 0954405420968161

34. Günay M, Meral T (2020) Modelling and multiresponse optimization for minimizing burr height, thrust force and surface roughness in drilling of ferritic stainless steel. Sādhanā 45(1):1-10

35. Taguchi G (1987) System of experimental design: engineering methods to optimize quality and minimize costs. UNIPUB/Kraus International Publications

36. Marichamy S, Saravanan M, Ravichandran M, Veerappan G (2016) Parametric optimization of electrical discharge machining process on $\alpha-\beta$ brass using grey relational analysis. J Mater Res 31(16):2531-2537

37. Marichamy $S$, Saravanan $M$, Ravichandran $M$, Veerappan $G$ (2016) Parametric optimization of EDM process on $\alpha-\beta$ brass using Taguchi approach. Russ J Non-Ferrous Met 57(6):586-598

38. Sivakandhan C, Loganathan GB, Murali G, Prabhu PS, Marichamy S, Krishnan GS, Pradhan R (2020) Material characterization and unconventional machining on synthesized Niobium metal matrix. Mater Res Express 7(1):15018

Publisher's Note Springer Nature remains neutral with regard to jurisdictional claims in published maps and institutional affiliations. 